\title{
Instinto predatório e o sentido do desenvolvimento econômico no Brasil Colônia: uma interpretação a partir de uma abordagem institucionalista vebleniana*
}

\section{Predatory instinct and the sense of economic development in Brazil Colony: an interpretation based on a Veblenian institutionalist approach}

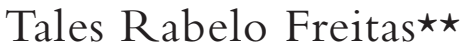

\begin{abstract}
Resumo: Este artigo tem como objetivo o resgate da teoria dos instintos deVeblen e, consequentemente, sua incorporação para a concepção de uma abordagem institucionalista alternativa para a interpretação das instituições e da dinâmica do sistema socioeconômico. Essa abordagem leva em conta os instintos aflorados em um sistema composto por: hábitos de emulação social, instrumentos de poder e um sistema de motivação presente no interior das organizações produtivas. Em seguida, utiliza-se desse novo modelo analítico para interpretar o sentido da dinâmica econômica e social estabelecida no período colonial brasileiro e seus impactos nas instituições que orientaram a trajetória de desenvolvimento nacional.
\end{abstract}

Palavras-chave: Institucionalismo. Instintos. Hábitos.

\begin{abstract}
This article aims to rescue the theory of Veblen's instincts and, consequently, its incorporation to the design of an alternative institutionalist approach to the interpretation of institutions and the dynamics of the socioeconomic system. This approach takes into account the instincts raised in a system composed of: habits of social emulation, instruments of power and a system of motivation present within productive organizations. Then, this new analytical model is used to interpret the meaning of the economic and social dynamics established in the Brazilian colonial period, and its impacts on the institutions that guided the national development trajectory.
\end{abstract}

Keywords: Institutionalism. Instincts. Habits.

JEL: B15. B52.

\footnotetext{
* Submissão: 09/08/2020 | Aprovação: 11/07/2021 | DOI: 10.29182/hehe.v24i3.761

$\star \star$ Doutor em Desenvolvimento Econômico pela Universidade Federal do Rio Grande do Sul. Brasil | ORCID: 0000-0002-7450-424X | E-mail: tales.rabelo@hotmail.com
} 


\section{Introdução}

Muitas abordagens institucionalistas têm analisado os impactos das formas de colonização - exploração e povoamento - nas instituições e trajetórias de desenvolvimento dos países. Participam dessa tese autores das mais variadas correntes: North (1959), Baldwin (1956), Engerman e Sokoloff (1997), Acemoglu, Johnson e Robinson $(2001,2002) .{ }^{1}$ É importante destacar também os escritos de Caio Prado Jr. (1942), que, embora não seja considerado um autor da ala institucionalista, concebeu uma interpretação convergente com esse arcabouço.

Entretanto, nenhuma dessas abordagens leva em conta as contribuições dos trabalhos do autor considerado o pai da teoria institucionalista:Thorstein Veblen. Este buscou desenvolver uma teoria de evolução econômica e institucional com linhas fundamentalmente darwinianas, tendo como marca o desvio de qualquer tipo de determinismo, inclusive o institucional. Sua principal questão era que todos os elementos que compõem a análise deveriam ser explicados a partir de relações causais cumulativas. Nesse sentido, mesmo que se considere as instituições como protagonistas na determinação da dinâmica econômica e social, é preciso conceber uma abordagem que as explique.

Para entender as instituições, Veblen aprofundou sua análise sobre a natureza humana, uma vez que se considera que aquelas surgem e se sustentam a partir da interação entre indivíduos. A abordagem do autor se concentrou fortemente sobre os aspectos das inclinações instintivas, as quais se configurariam como mecanismos definidores dos objetivos a serem perseguidos pelos hábitos e instituições.

O esforço de ligar as instituições - um mecanismo derivado da interação social - às inclinações humanas inatas deu origem à chamada teoria dos instintos. Veblen fez forte uso do componente instintivo em suas obras para explicar as instituições sociais; entretanto, essa parte de suas ideias foi amplamente negligenciada pelas abordagens institucionalistas que se desenvolveram posteriormente.

Porém, compreende-se que os instintos são componentes fundamentais do pensamento vebleniano para a análise institucional, e que há espaço para avançar na busca de um arcabouço teórico sistematizado a partir da conexão entre instintos e instituições. Para tal empreitada, deve-se ter em mente a

\footnotetext{
${ }^{1}$ Para uma revisão da literatura sobre os impactos da colonização na trajetória de desenvolvimento dos países, ver Monasterio e Ehrl (2015).
} 
relação de causação circular entre instintos e hábitos, uma vez que Veblen sempre preferiu o pensamento sistêmico em seus escritos, em detrimento do reducionismo dos economistas neoclássicos.

Nesse caso, se os instintos causam os hábitos, a relação contrária deve também ser trabalhada, ou seja, é preciso analisar os elementos institucionais e materiais que afetam a afloração instintiva dos indivíduos dentro da sociedade. Para tal, uma alternativa viável está na incorporação das ideias de John Kenneth Galbraith, cuja análise sobre as grandes corporações - mais especificamente o modo como estas são configuradas a partir dos instrumentos de poder e do sistema de motivação - permite a construção de um modelo que visará explicar as trajetórias de desenvolvimento das sociedades a partir das relações existentes entre instintos e instituições.

Assim, este trabalho tem como objetivo apresentar uma abordagem institucionalista alternativa para a leitura das instituições e regularidades do sistema econômico das sociedades, que leva em conta o resgate da teoria dos instintos do autor e, a partir desta, interprete o período colonial brasileiro e seus determinantes para a dinâmica institucional que direcionou o desenvolvimento econômico do país.

O artigo está composto de cinco seções, além desta introdução. A primeira apresenta uma breve análise da teoria dos instintos contida na obra de Veblen. Em seguida, na segunda seção, estabelecem-se algumas hipóteses sobre a relação entre instintos e instituições, como também o levantamento de alguns fatores determinantes da afloração instintiva, no qual serão incluídas algumas ideias de Galbraith. Na terceira seção se constrói uma abordagem institucionalista que leva em conta as inclinações afloradas na mente dos indivíduos e suas implicações na explicação da dinâmica econômica e social. Tais instintos serão evocados como resultado de um contexto configurado a partir de elementos que se referem ao sistema de motivação, instrumentos de poder e formas sociais de emulação. Em seguida, na quarta seção, será feito um exercício de interpretação do período colonial brasileiro a partir da abordagem institucionalista construída. Por fim, conclui-se o trabalho.

\section{A teoria dos instintos de Veblen}

A abordagem institucionalista de Veblen concebe alto grau de importância aos instintos, como componentes fundamentais da natureza humana, e sua interação com os hábitos. O primeiro trabalho do autor sobre o tema 
foi The instinct of workmanship and the irksomeness of labor (1898). Este foi o texto seminal que estabeleceu, antes mesmo da famosa "teoria da classe ociosa", as bases para a determinação da conduta humana na teoria vebleniana. $\mathrm{O}$ fundamento dos instintos volta a aparecer nos vários trabalhos do autor institucionalista, sendo inclusive considerado como categoria fundamental para o entendimento mais amplo das ideias do autor, podendo ser atribuída importância igual, senão maior, em comparação com as instituições (Cavalieri, 2009).

Diferentemente dos economistas neoclássicos, que formulam suas teorias partindo de uma natureza humana dada, passiva, imutável e de racionalidade hedonista, a abordagem institucionalista vebleniana compreende que os hábitos mentais, que estabelecem a intencionalidade, o comportamento e o discernimento, devem ser analisados a partir de processos de causação. Nesse contexto, a ênfase de Veblen nos instintos e hábitos para explicar a ação humana foi herdada de William James (1890) e William McDougall (1908), que buscaram conectar as formas habituais de agir e pensar, as quais são construídas socialmente, aos impulsos derivados da natureza humana.

Ao se utilizar da psicologia dos hábitos e instintos, Veblen se preocupou em distanciar sua compreensão da natureza humana de qualquer reducionismo (Hodgson, 2004, 2007). A incorporação dos instintos na análise evitou uma concepção de indivíduo redutível à estrutura social. Ou seja, as instituições condicionam os pensamentos e ações dos agentes, mas devem respeitar os limites impostos pelos impulsos instintivos. Por outro lado, o autor impõe limites sobre os quais os hábitos mentais e as atitudes das pessoas se tornam determinadas pelas condições fisiológicas, como também rejeita a ideia de que os fenômenos sociais possam ser explicados apenas a partir dos indivíduos. Logo, a natureza humana e, consequentemente, a estrutura social, respondem tanto pela dotação instintiva quanto pela estrutura institucional desenvolvida cumulativamente ao longo do tempo.

Dessa forma, se para os institucionalistas as instituições importam para a determinação da dinâmica econômica, para Veblen os instintos importam para a compreensão das instituições e de sua mudança.Tem-se que os hábitos mentais e instituições não pairam sobre o vazio, pois resultam das circunstâncias materiais e da fisiologia dos agentes (Hodgson, 1998, 2000). Essas interações não seguem objetivos aleatórios, mas sim definidos pelas propensões inatas, determinadas pela natureza do homem. Sem instintos, ou qualquer outro elemento associado à constituição biológica humana, não haveria forma de explicar o surgimento das instituições a partir da própria interação 
social, de forma que o seu conteúdo somente poderia ser associado a elementos externos, como a existência de uma ordem natural de nível superior ou mesmo alguma entidade divina.

Em termos gerais, os instintos, na abordagem vebleniana, são mais do que meras impulsões reflexivas, envolvendo também consciência e desencadeamento de reflexão para tomadas de decisões de níveis de complexidade mais altos. Nesse caso, a característica fundamental de um instinto é a sua capacidade de propor uma finalidade, de modo que a ação instintiva é uma categoria teleológica (Veblen, 1914).

Há vários princípios que cercam a relação entre instintos e hábitos na teoria deVeblen (1914), mas o geral é que os primeiros fornecem os propósitos e motivações das ações dos agentes, tanto no âmbito individual quanto em sociedade, enquanto os segundos configuram as formas de perseguir esses objetivos. O esquema envolvendo os instintos e hábitos na mente dos agentes começa com o momento no qual os fenômenos do ambiente - e neste incluem-se tanto a estrutura fisica quanto a institucional - afloram um conjunto de instintos, que determinam as finalidades desejadas pelos indivíduos.

Dependendo da conjuntura, outras propensões podem vir à tona, inclusive de caráter divergente entre si. Porém, os hábitos já estabelecidos selecionam qual ou quais propensões serão postas para atuar.Já nos casos em que não há constituído nenhum hábito, os instintos manifestados terão de ativar o processo cognitivo para, assim, configurar ações e formas de pensamento. Posteriormente, a habituação surge como consequência da reprodução constante dessas ações e modos de pensar. Nesse momento, ocorre uma espécie de enxerto do referido hábito com os instintos evocados, de modo que o primeiro "restringe o alcance da tendência em si, e nos impede de reagir a qualquer objeto que não seja usual” (James, 1890, p. 395). Aqui, os hábitos passam a manipular a percepção e a forma de reação, conduzindo a mente dos agentes sobre quais aspectos de um evento deverão ter mais atenção, enquanto outros deverão ser ignorados ou deixados em segundo plano.

Por sua vez, na medida em que os hábitos se tornam mecanismos de pensamento e ação aceitos pela comunidade, e passam a ser incorporados cada vez mais pelos demais indivíduos, estes se materializam em instituições. No esquema vebleniano, tem-se os hábitos como categorias de nível individual que, na medida em que vão se coletivizando, transformam em instituições (Cavalieri, 2009). Assim, Veblen (1899) conceitua instituições como hábitos mentais enraizados socialmente e que regulam as ações rotineiras dos indivíduos. 
É a partir da teoria dos instintos que Veblen $(1898,1914)$ atribui a existência de múltiplas finalidades que ditam as ações econômicas dos agentes. Seu modelo teórico permite que cada objetivo seja explicado a partir de relações de causa e efeito, de modo que cada instinto seja aflorado levando em conta a interação dos seres humanos com o ambiente material e social onde se encontram. Com isso, o autor desenvolveu tipificações de instintos que dominaram a mente dos indivíduos em cada etapa do desenvolvimento cultural e, assim, ditaram a dinâmica social e econômica. Cada propensão humana tem uma causa e, consequentemente, um efeito sobre o conjunto de hábitos e instituições.

O primeiro deles é o instinct of workmanship, traduzido como instinto para o trabalho eficaz. Para Veblen, o homem é um ser ativo, que age sempre em busca de um propósito, de modo que essa característica se estabelece como uma propensão instintiva canalizada para a realização de algum fim concreto e objetivo (Veblen, [1899] 2007). Tal propensão tem como finalidade a busca por eficiência no trabalho produtivo, aversão à futilidade e ações sem propósito. Conforme o autor, o instinto para o trabalho eficaz está presente em todos os agentes, sendo que a espécie humana somente pôde se adaptar e se desenvolver em seu meio ambiente por possuir essa propensão, a qual é considerada pelo autor "o traço mais genérico e duradouro da natureza humana” (Veblen, 1898, p. 190).

Em termos gerais, o instinto para o trabalho eficaz está em conflito com o impulso responsável pela aversão ao trabalho servil. Este último é chamado por Veblen de instinto para o esporte ou, como é comumente conhecido, instinto predatório. Tal propensão cria estímulos para atividades com o fim na valorização individual, cujo resultado é totalmente desnecessário perante o objetivo de manutenção das necessidades do grupo. Ou seja, está ligado às atividades que não têm relação com o processo produtivo, manifestando o desejo de demonstração de superioridade e, por vezes, de infringir dano, moral ou físico, aos adversários.

Os exemplos mencionados são as guerras, a caça de grandes presas, atividades esportivas, a busca por acumulação de bens e ativos financeiros, e o consumo conspícuo. Entretanto, a inclinação para ações com fins predatórios não é considerada, pelo autor institucionalista, dominante na natureza humana, pois sua afloração ocorre "apenas em uma espécie que distanciou todos os competidores, e mesmo assim ela prevalece apenas com a tolerância e dentro dos limites estabelecidos pelo instinto para o trabalho eficaz" (Veblen, 1898, p. 190). 
A inclinação predatória está intimamente ligada a outra propensão que, segundo as obras do autor, tem um papel tão fundamental no comportamento social humano quanto o instinto para o trabalho eficaz. Esta é a propensão para a emulação. É importante ter em mente que a emulação é uma propensão chave na teoria vebleniana, ganhando destaque em Theory of the leisure class (1899). Pode-se dizer que, na natureza humana, ela assume um nível de dominância e importância tão fundamental quanto o instinto para o trabalho eficaz. Nas palavras do autor: "Com exceção do instinto da autopreservação, a propensão para a emulação é provavelmente o mais forte, o mais alerta e persistente dos motivos econômicos" (Veblen, [1899] 2007, p. 110, tradução nossa). Cavalieri, (2009, p. 361) sintetiza o conceito de emulação como sendo a

[...] atitude de um indivíduo de comparar-se com os demais desejando superá-los, sempre em algum aspecto que o faça ser coletivamente mais estimado, mais positivamente reconhecido em relação aos outros membros da comunidade.

Um ponto importante do esquema vebleniano, cuja inspiração está em James (1890), é que os diversos instintos estão presentes em forma de uma miscelânea, sendo impossível sua separação em estado bruto. São os hábitos os responsáveis pela delimitação e canalização da força teleológica presente nos instintos. Essa forma "miscelânica" permite processos de imbricação entre os instintos e, consequentemente, faz emergir novas propriedades. ${ }^{2}$ É nesse sentido que se pode auferir o instinto predatório como uma categoria instintiva emergente, derivada da contaminação do instinto para o trabalho eficaz pela propensão à emulação. Embora tenha sua origem no instinto para o trabalho eficaz, o instinto predatório é diferente por perseguir objetivos distintos da eficiência produtiva. ${ }^{3}$

SegundoVeblen ([1899] 2007), o instinto predatório, aliado à propensão para a emulação, forma a base para o comportamento de emulação pecuniária, o qual, por sua vez, é demonstrado a partir dos hábitos de ócio e consumo conspícuos. O primeiro se refere à abstenção de quaisquer ocupações laborais, e o engajamento em atividades que demonstram esse afastamento do trabalho produtivo, como a religião, os esportes e a arte. Nas palavras do autor, "A

\footnotetext{
2 "In instinctive action the individual acts as a whole, and in the conduct which emerges under the driving force of these instinctive dispositions the part which each several instinct plays is a matter of more or less, not of exclusive direction. They must therefore incontinently touch, blend, overlap and interfere, and can not be conceived as acting each and several in sheer isolation and independence of one another." (Veblen, 1914, p. 11).

${ }^{3}$ A origem do instinto predatório está em Veblen (1898).
} 
abstenção conspícua do trabalho torna-se, portanto, a marca de realização pecuniária superior e um convencional índice de reputação" (Veblen, [1899] 2007, p. 30, tradução nossa). Já o consumo conspícuo seria a demonstração emulativa a partir do desperdício ostensivo. Ou seja, refere-se à ostentação de objetos caros, mas de pouca utilidade, com finalidade essencialmente emulativa. Pode-se afirmar, portanto, que ambos os hábitos citados são estabelecidos como a busca pela expressão da diferenciação das classes sociais, pautadas pelos instintos da emulação predatória.

Veblen ([1904] 1978,1921) viu um irrepreensível conflito entre o instinto predatório e o do trabalho eficaz, que apoiaria a dicotomia entre as necessidades industriais/produtivas da sociedade e a dos negócios corporativos. A forma desse conflito emerge com o avanço material das sociedades. A evolução das capacidades produtivas da humanidade fez com que o nível de produção corrente ultrapassasse o nível de subsistência, permitindo a geração de excedentes (Veblen, 1898).

Consequentemente, as novas condições permitiriam a afloração de hábitos baseados no instinto predatório, uma vez que os indivíduos passariam a disputar a posse de tais excedentes. Na medida em que uma comunidade não precisaria mais que toda a sua população se dedicasse ao trabalho de subsistência, abrir-se-ia a possibilidade para uma maior divisão de classes, como também de novas práticas de administração da produção (Veblen, [1899] 2007, [1904] 1978).

Sobre os hábitos de gerenciamento industrial, Veblen ([1904] 1978) estabelece que as novas formas de administração visavam ao acúmulo de riqueza, em especial na forma de ganho monetário, como finalidade última do processo produtivo. Com isso, argumenta-se que a dominância do instinto predatório direcionaria a estrutura produtiva das sociedades para a eficiência financeira e não material. Como resultado, tem-se que a mentalidade predatória presente na administração das organizações prejudicaria o bem- estar da sociedade, restringindo a produtividade, o avanço tecnológico e o uso eficiente dos recursos. Por conseguinte, isso limitaria os objetivos derivados do instinto para o trabalho eficaz como os esforços para o aumento da eficiência e geração de utilidade. O resultado final é um quantum de oferta muitas vezes aquém do nível desejável pela sociedade.

Diante do que se apresentou até então, percebe-se que a teoria dos instintos de Veblen pode ser muito importante para os avanços da agenda de pesquisa institucionalista, principalmente no que se refere ao tema do desen- 
volvimento econômico. ${ }^{4}$ Considerando os instintos como componente fundamental para a definição dos objetivos e motivações por trás das ações humanas, compreende-se que o resgate e incorporação desse arcabouço teórico pode contribuir profundamente para melhorar a compreensão dos aspectos referentes ao papel das instituições na conformação das trajetórias de desenvolvimento, como também entender melhor os processos de mudança.

Com isso em mente, buscar-se-á avançar, nas próximas seções, em direção a uma abordagem institucionalista que incorpore os componentes dos instintos de Veblen, seus impactos na análise das instituições e das trajetórias de desenvolvimento econômico.

\section{Em busca de uma sistematização: estabelecendo algumas hipóteses}

Da análise feita sobre a teoria dos instintos de Veblen e as interações entre esse componente e as instituições, pode-se, em um primeiro momento, estabelecer duas hipóteses básicas: 1) é o instinto para o trabalho eficaz o impulso principal que direciona a ação humana no sentido de realizar atividades relacionadas à produção, abarcando a busca pela inovação tecnológica e melhorias de produtividade;2) o instinto predatório limita os hábitos e ações derivados do instinto para o trabalho eficaz, orientando os hábitos e instituições das sociedades para perseguirem a emulação pecuniária.

Essas hipóteses estão explícitas em praticamente todos os escritos do autor, uma vez que o conflito entre a inclinação predatória e o instinto para o trabalho eficaz se configura como núcleo duro fundamental para a abordagem institucionalista vebleniana, embora a maior evidência esteja em The engineers and the price system (1921).

Entretanto, os instintos se configuram como um fator extremamente abstrato e de difícil identificação de seus componentes na análise da dinâmica socioeconômica. Isso, por sua vez, cria empecilhos para o uso dos instintos em análises econômicas, pois ainda não há definidos critérios mais específicos para uma melhor identificação dos tipos de instintos que dominam cada etapa da vida econômica de uma determinada sociedade.

Por outro lado, isso não invalida as contribuições de Veblen, o qual fez

\footnotetext{
${ }^{4}$ Para uma discussão mais aprofundada sobre os avanços de Veblen em relação às modernas abordagens institucionalistas de Douglass North e de Ha-Joon Chang, ver a tese de Freitas (2019).
} 
um ótimo trabalho na definição das categorias instintivas, como também seus efeitos no desenvolvimento das sociedades ao longo da história, e especificamente na economia capitalista que emergiu na virada do século XIX para o século XX.

Sendo assim, entendendo a importância que as contribuições da teoria dos instintos de Veblen podem trazer para a economia institucionalista, é preciso, antes de tudo, avançar no intuito de sistematizar os elementos da abordagem vebleniana, incorporando outros conceitos concretos que permitem capturar a essência abstrata dos instintos.

Esses conceitos devem permitir explicar o conjunto de motivações que direcionam as ações econômicas dos agentes, como o trabalho e o investimento produtivo, e apresentar relação de causalidade com a estrutura institucional, formal e informal, da sociedade.

Um autor que fez bastante uso desse tipo de conceito em sua análise das organizações produtivas foi John Kenneth Galbraith. ${ }^{5}$ Em O novo estado industrial (1967), Galbraith analisou como a dinâmica das grandes corporações que emergiram no capitalismo norte-americado a partir do século XX eram determinadas por dois fatores fundamentais: sistemas de motivação e instrumentos de poder.

Assim como Veblen, Galbraith entendia que os mecanismos de mercado eram insuficientes para explicar tanto a dinâmica capitalista quanto a das organizações. A insistência no padrão de distribuição de renda e riqueza como um dos elementos determinantes da organização socioeconômica e da questão da eficácia econômica é um dos pontos principais que liga a contribuição teórica de ambos os autores (Stanfield; Wrenn, 2005).

Para Veblen, o desenvolvimento do sistema capitalista se desdobra a partir dos conflitos entre a sabotagem, promovida pelo instinto predatório, e a busca pela eficiência, movida pelos imperativos do instinto para o trabalho eficaz. Nesse sentido, os escritos de Galbraith focam em explicar como o padrão de organização e distribuição da economia capitalista é determinado a partir do resultado da estrutura de poder social e político, contrapondo, com isso, o reducionismo da economia neoclássica, que opera apenas no nível dos mercados.

\footnotetext{
${ }^{5}$ Vale lembrar que Galbraith não é considerado essencialmente um economista institucionalista. Embora tenha sido muito influenciado porVeblen, é notório que outros autores foram muito importantes para seus escritos, como John Maynard Keynes, Karl Marx, Adam Smith, entre vários outros.
} 
Sendo assim, é a partir da incorporação dos conceitos de Galbraith ([1967] 1982), mais especificamente os sistemas de motivação e instrumentos de poder, que se buscará sistematizar os mecanismos de determinação dos instintos aflorados dentro das estruturas sociais e, com isso, explicar o sentido das instituições e das sociedades.

\subsection{Sistemas de motivação e instrumentos de poder}

Conforme explicita Galbraith ([1967] 1982), os sistemas de motivação são o conjunto de incentivos empregados para induzir os indivíduos a agir e realizar determinado propósito.Já os instrumentos de poder são os mecanismos utilizados por um grupo de agentes para criar esses incentivos na mente dos outros.

O seu conceito de "sistema de motivação" é composto de quatro meios fundamentais de estimular os indivíduos a se aliarem às organizações e, assim, submeterem-se ao trabalho proposto.

O primeiro é a ameaça de punição, também denominada de compulsão. Essa é uma das formas mais antigas de impor um determinado tipo de atividade a alguém. O sistema latifundiário, que vigorou no período colonial brasileiro, é um típico exemplo do uso da punição para forçar mulheres e homens negros, em regime de escravidão, a trabalharem por longas horas em tarefas extremamente árduas. Os que descumpriam as regras e não entregavam as cotas diárias de produção eram condenados a sofrer os mais diversos tipos de tortura.Assim, pelo medo das represálias, os indivíduos aceitam os objetivos que lhes são impostos. Porém, esse tipo de motivação, é menos frequente nas sociedades modernas.

O segundo tipo de motivação mencionado por Galbraith ([1967] 1982) é a recompensa pecuniária. Nesse caso, pode-se comprar o esforço de alguém para a realização de atividades ligadas aos objetivos desejados pelo comprador. É o tipo de motivação mais comum, senão dominante, nas sociedades modernas, e que se configura a partir do trabalho assalariado.

O terceiro motivo, e talvez o mais presente entre todas as etapas de desenvolvimento das sociedades humanas, é o da identificação. $O$ incentivo para se aliar a uma organização ocorre pelo nível com que se está identificado aos objetivos perseguidos. Conforme Galbraith ([1967] 1982, p. 105), “o indivíduo, ao associar-se ao grupo, pode concluir que os objetivos deste são superiores aos seus", de forma que os agentes se submetem à realização das atividades propostas sem a necessidade de represálias ou maiores compensações. 
A última motivação é denominada de adaptação, a qual se refere ao indivíduo que aceita servir à organização "não porque lhe considere os objetivos superiores aos seus, mas porque espera torná-los mais parecidos com os seus" (Galbraith, [1967] 1982, p. 105). É o caso de jovens, dominados pelo forte espírito de conquista, que ingressam nos programas de trainee das grandes corporações na esperança de, algum dia, tornarem-se executivos, os chamados CEOs (chefe executivo de ofício), e ditarem as estratégias de atuação da organização. No geral, é mais voltado para aqueles que têm o desejo de poder, no intuito de submeter outros agentes às suas vontades.

Essas motivações, postas por Galbraith como requisitos para a ação produtiva, são facilmente conciliáveis com as propensões humanas do arcabouço teórico de Veblen e dos autores da psicologia dos hábitos e instintos. À primeira vista, pode-se fazer as seguintes conexões: 1) a motivação da compulsão se associa à impulsão da autopreservação, uma vez que esta é aflorada pela ameaça de morte, violência ou da privação de recursos essenciais para a subsistência; 2) já o trabalho por remuneração é acompanhado por um mix entre a necessidade da subsistência e da emulação pecuniária, pois é através da instituição do dinheiro que os homens conseguem emular padrões de consumo, ostentar riqueza e, consequentemente, conquistar certa estima perante seus pares; 3) por fim, a motivação por identificação se relaciona com o instinto para o trabalho eficaz na medida em que os indivíduos agem em conformidade com os próprios objetivos, mesmo respondendo ao chamado de outros. Esta última correlação é explicada pelo argumento de que o instinto para o trabalho eficaz evoca a repulsa à futilidade e ao trabalho sem propósito, de modo que a identificação com um propósito útil se torna um importante motor para impulsionar uma parte dos agentes a atuarem. Já a motivação da adaptação está associada ao instinto de emulação, uma vez que o desejo pelo poder de ditar os rumos da organização vem da busca por ser estimado dentro da sociedade. Entretanto, essa motivação por si só não permite definir o tipo de emulação a ser realizada, se conectado com o instinto predatório ou para o trabalho eficaz.

Galbraith ([1967] 1982) também busca explicar os fatores determinantes dos tipos de motivações que irão imperar nas organizações. Para ele, o poder de motivar a ação econômica está atrelado a três tipos de instrumentos fundamentais: a personalidade, a propriedade e a organização.

Em termos gerais, a personalidade como instrumento de poder se refere à “qualidade do fisico da mente, de oratória, de firmeza moral ou de qualquer 
outra característica pessoal que dá acesso a um ou mais instrumentos do poder" (Galbraith, 1984, p. 6). É referente ao poder de condicionar as mentes de outros e, com isso, subordiná-los aos objetivos daqueles que dominam a capacidade de persuasão, estando fortemente associado à motivação pela identificação. Essa configuração do instrumento da personalidade se manifesta a partir do domínio da oratória, da presença do carisma e do talento para fascinar as pessoas com opiniões e ideais das mais diversas. Como exemplo, Galbraith (1984) aponta os feitos de Moisés, Confúcio,Aristóteles, Platão, Jesus, Marx e Gandhi, os quais eram desprovidos de força fisica, mas conseguiam, e ainda conseguem, mover multidões com suas ideias.

A posse de propriedade entrega certo nível de poder, uma vez que ela consegue induzir à submissão aqueles que aceitarem a recompensa oferecida. Para o autor, entre as três fontes de poder, a propriedade é a mais objetiva e comum, pois ela consegue "submeter a vontade de uma pessoa a outra através da aquisição franca e direta" (Galbraith, 1984, p. 49). Esse instrumento é frequentemente associado com a motivação da remuneração e, em alguns momentos, da compulsão.

Já a organização é estabelecida, conforme os escritos de Galbraith (1982, 1984, 1993, 1998), como principal fonte de poder na sociedade moderna. Ela é definida como sendo "um número de pessoas ou grupos, unidos para algum propósito ou trabalho" (Galbraith,1984, p. 58). Está ligada mais intensamente ao poder condicionado, mas também permite motivar a ação dos outros a partir da recompensa financeira e, em menor nível, da punição física. Os melhores exemplos de organizações poderosas, e que tiveram enormes efeitos na vida social ao longo da história, são: a Igreja, o Estado e as corporações. No geral, os indivíduos se associam às organizações por se identificarem com seus objetivos. Por entenderem que estes são mais valiosos e honoríficos do que qualquer propósito individual, acabam incorporando os objetivos do grupo aos seus e, com isso, submetendo-se às suas imposições.

Por outro lado, a organização é o instrumento de maior complexidade e, por isso, consegue impor suas vontades através das outras motivações. Essa premissa é apoiada no argumento de Charles E. Lindblom (1977), que estabelece a supremacia da organização diante das demais fontes de poder. Em outras palavras, "a propriedade e a personalidade só produzem resultado com o apoio da organização” (Galbraith, 1984, p. 57).Assim, a organização também faz uso da propriedade e da personalidade para exercer seu poder, principalmente quando busca impor objetivos aos indivíduos que não pertencem ao seu conjunto. 
Uma empresa conquista boa parte do seu poder externo por meios compensatórios - oferecendo ao público algo que vale o dinheiro despendido. Esse dinheiro, por sua vez, compra o esforço dos que trabalham na empresa e aumenta o poder compensatório sobre eles exercido. (Galbraith, 1984, p. 66)

Apesar de a organização permitir a motivação pela compulsão e remuneração, a sua capacidade de impor suas vontades aos demais segmentos da sociedade dependerá do grau com que os indivíduos da própria organização se submetem aos objetivos estabelecidos por esta. Para Galbraith (1984, p. 60), é a partir da dedicação, evocada pela identificação, entre os membros internos que "advém a capacidade da organização para impor sua vontade externamente. Uma depende da outra. Esta é a característica invariável de todo exercício do poder organizado".

Por fim, resta uma última hipótese para fechar o modelo. Até o momento se tem que os instintos - que são componentes capazes de definir os objetivos a serem realizados pelas instituições - são aflorados dentro de um sistema de motivação, e que estes são definidos pelos instrumentos de poder dominantes dentro das organizações e das sociedades. Logo, resta explicar o que determina os meios de poder mais eficientes para motivar os agentes.

Para isso, será pressuposto que os instrumentos de poder mais eficientes serão aqueles que estiverem atuando em conformidade com as formas sociais de emulação. O sistema de motivação, que regula a ação econômica de firmas e indivíduos, tem forte conexão com as instituições sociais, mais especificamente aquelas responsáveis pela realização do instinto para a emulação. Logo, os tipos de instrumentos mais eficazes para impor ações aos agentes são aqueles que estão em conformidade com os anseios derivados das formas sociais de emulação.

Por exemplo, em sociedades dominadas pela emulação pecuniária, a propriedade será naturalmente o meio de poder dominante, pois a remuneração é fundamental como motivação para qualquer atividade, uma vez que as pessoas aqui irão se comparar umas com as outras a partir dos hábitos de consumo e ostentação de riqueza. Já naquelas em que a emulação é realizada via demonstração de competências, habilidades e realizações de serventia, é de se esperar que a organização e a personalidade se constituam como meios mais eficazes de motivação, por permitir maior identificação dos indivíduos com os resultados de suas atividades. 


\section{A definição do modelo: relações causais e tipologias}

É importante deixar claro que este trabalho vai no sentido de avançar sobre a necessidade de a teoria econômica institucionalista desenvolver modelos para analisar a mudança e os rumos perseguidos pela sociedade. Esse esforço vai na direção das críticas de que o antigo institucionalismo, oriundo dos escritos de Veblen, não oferece uma abordagem sistemática e viável da teoria econômica. ${ }^{6}$ Para Hodgson (1996), tais críticas são equivocadas, pois o autor foi o primeiro cientista social a tentar desenvolver uma teoria de evolução econômica e institucional com linhas fundamentalmente darwinianas. Entretanto, por apresentarem em suas análises uma tendência maior à descrição do que à sistematização, os antigos institucionalistas não conseguem desenvolver juntos um núcleo teórico sistemático.

Conforme definido na seção anterior, os elementos a serem tratados e as hipóteses sobre cada um, o próximo passo será o de avançar a uma abordagem institucionalista que permita analisar a dinâmica econômica e social considerando os seguintes elementos: $a$ ) as fontes de poder; $b$ ) sistema de motivação; c) inclinações instintivas afloradas pela experiência e condições ambientais; e d) as formas sociais de emulação.

É preciso ter em mente que todos esses fatores estão intimamente entrelaçados, com sentidos multidirecionais. A começar pelas fontes de poder, argumenta-se que estas têm a capacidade de interferir no sistema de motivação que determinará os meios utilizados para coagir os indivíduos a se associarem às organizações. Por sua vez, as motivações são mecanismos importantes para definir as experiências dos agentes e, consequentemente, aflorar as inclinações instintivas necessárias para os desdobramentos das ações e do processo de habituação. As instituições, definidas como hábitos mentais enraizados, orientadas para a perseguição de objetivos derivados dos instintos, e configurando as formas sociais de emulação, surgem desse contexto.

Dessa forma, estabelecem-se os mecanismos pelos quais os instrumentos de poder podem afetar as instituições sociais e constrangê-las, a partir das experiências vivenciadas na produção, para se adequarem aos desejos da organização. A motivação pecuniária, derivada do poder da propriedade, pode aflorar nos trabalhadores propensões predatórias, que servem de base para hábitos de ócio e consumo conspícuos, impactando negativamente no grau

\footnotetext{
${ }^{6}$ Hodgson coloca esta questão da seguinte forma: “American institutionalism has bequeathed no integrated theoretical system of the stature or scope of that of Karl Marx, Alfred Marshall, Léon Walras, or Vilfredo Pareto." (Hodgson, 1998, p. 167).
} 
de honorabilidade dos hábitos sociais de serventia e busca de propósito útil, baseados no instinto para o trabalho eficaz.

Por outra perspectiva, ocorre que as fontes de poder podem também ser selecionadas pelo ambiente institucional. Os hábitos sociais de emulação têm ampla capacidade de definir se o instrumento de poder mais eficiente será o uso da propriedade ou da personalidade, juntamente com os mecanismos da organização, no processo de persuasão. Em uma sociedade na qual a emulação se dá com base no nível de eficiência e serventia, é de se esperar que os instrumentos de poder mais habilitados para a persuasão sejam aqueles ligados à motivação da identificação, como é o caso da personalidade e da organização, ficando a propriedade e a remuneração em segundo plano.

Todas essas relações podem ser resumidas a partir do fluxograma apresentado na Figura 1. Aqui, os instintos aflorados dentro do sistema de motivação fornecem o sentido das instituições sociais, as quais definem os hábitos de emulação social, que, por seu turno, selecionará os instrumentos de poder mais eficazes para motivar os agentes.

\section{Figura 1 - Relação causal circular entre os elementos componentes}

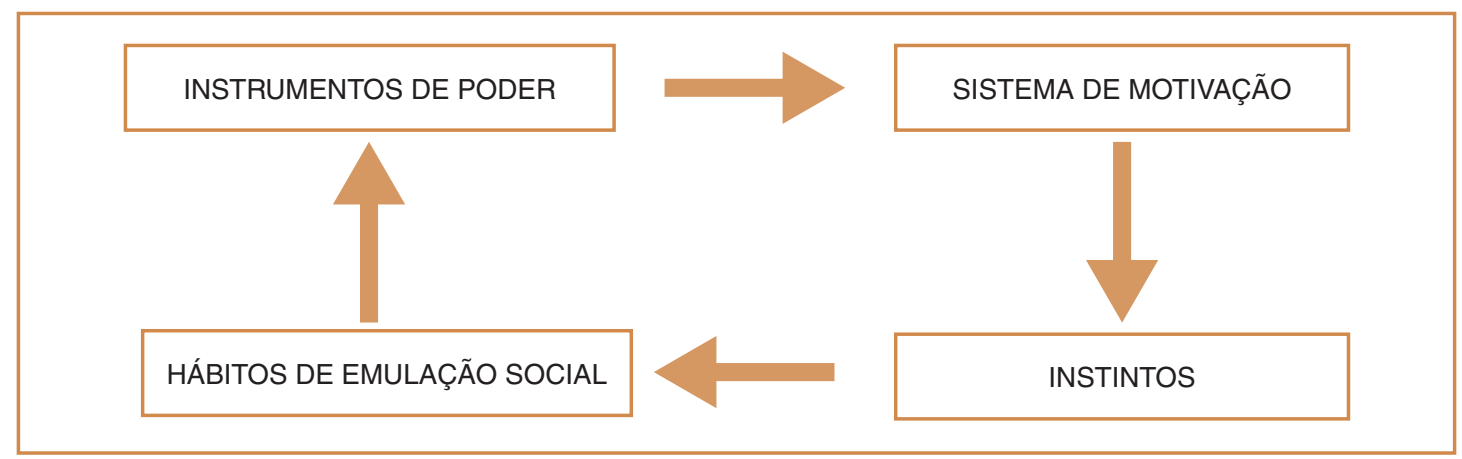

Fonte: Elaboração própria.

Não há um uma ordem hierárquica na determinação dos elementos considerados, de modo que não se pode definir quem veio primeiro. Essa análise institucionalista deve levar em conta a existência de uma relação mútua entre instintos, hábitos de emulação, sistema de motivação e instrumentos de poder. Além disso, a mudança em um desses componentes pode implicar a transformação do sistema como um todo.

Tendo em mente o caráter sistêmico dessa abordagem, compreende-se adequada a concepção de algumas tipologias acerca de configurações possíveis 
entre os elementos desse sistema, no intuito de determinar a dinâmica econômica e social de um povo. O primeiro esquema é representado por uma sociedade em que a propriedade é o principal instrumento de poder. Esta é apoiada pelas instituições da propriedade absenteísta e do ócio e consumo conspícuos, cuja base é o instinto predatório. Como resultado, tem-se um sistema de motivação que incentiva o trabalho e a associação às organizações a partir do ganho pecuniário e/ou pela motivação da compulsão. Nesse caso, as formas de emulação social são direcionadas pelos imperativos do capital, de modo que a cultura e demais instituições são dominadas pelos objetivos e mecanismos do sistema de mercado.

Já a segunda configuração é exposta como fruto da dominância do instinto para o trabalho eficaz. Aqui, o poder é realizado pelo instrumento da personalidade e da organização, e os indivíduos são persuadidos pela motivação da identificação. Os hábitos de emulação social são configurados para perseguirem a capacidade técnica e ações imbuídas de propósito de serventia. Por fim, no nível macro as instituições de propósito comunitário dominam os rumos da atividade econômica. Ambas as tipologias são resumidas no Quadro 1.

\section{Quadro 1 - Mecanismos definidores dos sentidos das trajetórias de desenvolvimento}

\begin{tabular}{|c|c|c|c|c|}
\hline Tipologia & $\begin{array}{c}\text { Instrumento } \\
\text { de poder }\end{array}$ & $\begin{array}{c}\text { Sistema de } \\
\text { motivação }\end{array}$ & $\begin{array}{c}\text { Propensão } \\
\text { instintiva }\end{array}$ & $\begin{array}{c}\text { Formas de } \\
\text { emulação }\end{array}$ \\
\hline$(1)$ & Propriedade & $\begin{array}{c}\text { Pecuniário/ } \\
\text { Compulsão }\end{array}$ & $\begin{array}{c}\text { Instinto } \\
\text { predatório }\end{array}$ & $\begin{array}{c}\text { Ócio e consumo } \\
\text { conspícuos }\end{array}$ \\
\hline$(2)$ & $\begin{array}{c}\text { Personalidade/ } \\
\text { Organização }\end{array}$ & Identificação & $\begin{array}{c}\text { Instinto para o } \\
\text { trabalho eficaz }\end{array}$ & $\begin{array}{c}\text { Capacidade } \\
\text { técnica/Utilidade }\end{array}$ \\
\hline
\end{tabular}

Fonte: Elaboração própria.

O exercício de sistematização desses parâmetros para a explicação da dinâmica das sociedades não pode negligenciar a análise histórica.É inclusive por esta que se verifica como esses padrões ocorrem e se modificam. Além disso, não se pressupõe a existência de configurações rígidas e preestabelecidas para cada caso, uma vez que é da natureza da teoria institucionalista lidar com sistemas evolucionários. Esses padrões são construídos historicamente, pelas experiências vivenciadas pelos indivíduos, e se transformam a partir de choques oriundos do ambiente social, material e das próprias instabilidades endógenas.

No esquema trabalhado aqui, os instintos são considerados como parâmetros definidores da direção da trajetória do sistema, podendo ser no 
sentido da acumulação pecuniária, derivada da propensão predatória, ou na lógica fornecida pelo instinto para o trabalho eficaz, que atua como base para a formação de hábitos que visam à eficiência e utilidade da atividade econômica para fins que vão além do acúmulo material. Já os instrumentos de poder e o sistema de motivação são mecanismos de reforço e seleção das propensões instintivas afloradas na mente dos participantes das organizações. Para que atuem como tal, deve haver uma consonância entre o sistema de motivação proposto pelas instituições econômicas e as formas de emulação social. A não observância dessa conexão gerará atritos no padrão institucional, podendo aumentar a frequência das mudanças sistêmicas.

Outra observação é que esses modelos são representativos de dois tipos de trajetórias de desenvolvimento radicalmente opostas. Logo, atenta-se para a possibilidade de se verificar padrões institucionais que se estabeleçam no hiato das duas tipologias definidas. Isso é visto, por exemplo, nos escritos de Galbraith ([1967] 1982), que concebe a tecnoestrutura norte-americana como configurada por um mix de componentes dos dois modelos: 1) instrumento de poder:propriedade e personalidade;2) motivação:pecuniária e identificação; 3) hábitos sociais de emulação: com base na emulação pecuniária (instinto predatório) e capacidade técnica (instinto para o trabalho eficaz).

Tendo em mente o modelo exposto até o momento, compreende-se que os avanços feitos até aqui podem ser úteis para a análise das instituições brasileiras e seus efeitos na trajetória de desenvolvimento econômico. Para isso, é necessário analisar os elementos propostos e verificar em qual tipologia o caso brasileiro melhor se enquadra. Ou seja, um processo orientado pelo instinto predatório ou para o trabalho eficaz.

É isso que este artigo tratará na seção seguinte. A partir da análise de autores clássicos da literatura brasileira, mais especificamente Caio Prado Jr. e Sérgio Buarque de Holanda, analisar-se-ão elementos fundamentais associados ao sistema de motivação e os instrumentos de poder que estiveram por trás das instituições que orientaram o processo de desenvolvimento nacional.

É importante deixar claro que, embora as obras desses intérpretes do Brasil não tenham recebido qualquer influência direta dos escritos Veblen, é possível identificar elementos compatíveis em suas análises da dinâmica econômica brasileira com o autor institucionalista. Nesse caso, o ponto especial a ser explorado se refere às motivações que orientaram as ações dos agentes e o surgimento e fortalecimento dos fatores que orientaram as instituições, tanto formais quanto informais. 


\section{O instinto predatório e o sentido da colonização brasileira}

Como já é comumente conhecido, o Brasil é um país cuja formação foi iniciada na primeira parte do século XVI, quando Portugal estabeleceu seus primeiros assentamentos na região nordeste da América Latina. Embora houvesse várias comunidades indígenas no território, elas eram independentes, não havendo qualquer entidade política unificada instituída antes da chegada dos Europeus. Assim, pode-se afirmar que as instituições que emergem com a chegada dos portugueses no Novo Mundo apresentam como base as inclinações afloradas pelas experiências desses indivíduos na região até então desconhecida.

O sentido do processo de exploração do Novo Mundo está expresso nos trabalhos de Caio Prado Jr., mais especificamente na sua Formação do Brasil contemporâneo, de 1942. O esforço de definir o sentido da colonização portuguesa nos trópicos é fundamental para compreender a história brasileira. Já nas primeiras páginas de seu livro, Caio Prado Jr. ([1942] 2017,p. 11) deixa claro essa importância:

Quem observa aquele conjunto, desbastando-o do cipoal de incidentes secundários que o acompanham sempre o fazem muitas vezes confuso e incompreensível, não deixará de perceber que ele se forma de uma linha mestra e ininterrupta de acontecimentos que se sucedem em ordem rigorosa, e dirigida sempre numa determinada orientação. É isto que se deve, antes de mais nada, procurar quando se aborda a análise da história de um povo, seja aliás qual for o momento ou o aspecto dela que interessa, porque todos os momentos e aspectos não são senão partes, por si só incompletas, de um todo que deve ser sempre o objetivo último do historiador, por mais particularista que seja.

Este "sentido da história de um povo", a que Caio Prado Jr. se refere, converge fortemente com a categoria dos instintos humanos que Veblen utiliza para definir a orientação das instituições. O referencial teórico vebleniano, utilizado neste artigo, em conjunto com as contribuições de Galbraith, deixa claro que as inclinações humanas, afloradas pela experiência de vida da sociedade, estão intimamente ligadas com as instituições que determinam as formas de emulação e o sistema de motivação que regula a atividade produtiva.

Ambos os autores também entendem que os fatores que determinam o sentido de uma sociedade podem mudar.Veblen enfatiza bem a mudança pela qual as sociedades humanas passaram à medida que o avanço tecnoló- 
gico permitiu a criação de excedentes produtivos, de modo que uma parcela do grupo pudesse se abster do trabalho produtivo e, com isso, se aventurassem em atividades de cunho predatório. Já Caio Prado Jr. menciona a mudança de sentido que Portugal sofreu na passagem do século XIV para o século XV. Em linha com o autor, até o século XIV, a história do país europeu se desdobrou com base nos esforços da "luta que teve de sustentar, para se constituir, contra a invasão árabe que ameaçou num certo momento todo o continente e sua civilização" (Prado Jr., [1942] 2017, p. 11).Já ao longo do século XV há uma mudança de rumo quando Portugal, já constituído territorialmente, adquire condições para se transformar em um país marítimo, desligando-se do restante do continente e desenvolvendo empresas fortes capazes de se aventurarem no ultramar, consolidando-se, assim, como uma importante potência colonial.

Essa mudança de rota permite a afloração de inclinações pecuniárias na mente de uma parcela da sociedade portuguesa, e é a partir dessa mentalidade que o país explora as regiões descobertas no Novo Mundo. Toda a empreitada das atividades marítimas visava ao proveito de uma rota que pudesse trazer lucros para aqueles que, a partir dela, entrassem em contato com o mercado de especiarias das Índias. Dessa forma, o "incidente" do descobrimento das novas terras na América do Sul pela empresa comercial portuguesa não pôde resultar em outra coisa que não a exploração com fins pecuniários.

O espírito predatório com o que se tratou a região tropical se torna evidente pelas circunstâncias do processo de povoamento. Num primeiro instante, a América se estabeleceu como um obstáculo para a realização do plano inicial de encontrar o Oriente. Os esforços iniciais na região foram os de encontrar uma passagem para o pacífico. "A ideia de povoar não ocorre inicialmente a nenhum. É o comércio que os interessa, e daí o relativo desprezo por este território" (Prado Jr., [1942] 2017, p. 13). Com o tempo, a ideia de povoar a nova região surge como uma necessidade diante das ameaças de outros povos europeus, em especial a França, a qual questionava a validade do bilateral Tratado de Tordesilhas.

Como não havia interesse de constituir ali uma nação por parte dos portugueses, o processo de povoamento só se tornou viável com o estabelecimento de uma atividade econômica lucrativa, que no caso seria a agricultura. A diversidade de condições naturais se revelou como um forte estímulo ao possibilitar a produção de gêneros que eram escassos na Europa. Entretanto, a finalidade produtiva com que os colonizadores se aproximam nos trópicos 
em nada tem como base a inclinação para o trabalho eficaz, mas sim uma orientação puramente predatória. Conforme Caio Prado Jr. ([1942] 2017, p. 23), "o colono europeu não traria com ele a disposição de pôr-lhe a serviço", mas sim "viria como dirigente da produção de gêneros de grande valor comercial, como empresário de um negócio rendoso".

Fazendo uso dos termos veblenianos, a propriedade absenteísta se institui como principal forma de organização da vida social e econômica da colônia. Essa instituição tem como base a afloração do instinto predatório e estabelece o hábito de possuir bens e fatores de produção que não são diretamente trabalhados pelos proprietários, cuja finalidade é puramente o ganho pecuniário (Cavalieri, 2009). A propriedade absenteísta, como instituição orientadora da vida na colônia portuguesa na América do Sul, tem dois determinantes principais: a) a alta concentração da propriedade; b) a falta de identificação com o novo território como motivação para a empreitada que se viera a se realizar.

A elevada concentração da propriedade se deve ao sistema administrativo adotado pela Coroa na tarefa de colonização. $\mathrm{O}$ sistema foi o das capitanias hereditárias, no qual a Coroa delega a tarefa de colonização e exploração de vastas áreas a particulares a partir da doação de lotes de terra com posse hereditária. Assim, a metrópole dividiu o Brasil em quatorze capitanias. Como se desconhecia o interior do território, a saída foi estabelecer faixas litorâneas paralelas desde a costa e seguindo região adentro. Todos os beneficiados faziam parte da pequena nobreza lusitana, sendo sete deles membros destacados nas campanhas na África e na Índia e quatro altos funcionários da corte. O sistema previa ainda que o donatário tivesse o poder supremo e de jurisdição sobre sua capitania, tendo o direito de desenvolver a terra e escravizar indígenas de acordo com sua própria vontade (Schwarcz; Starling, 2015).

Já a falta de predisposição inicial daqueles que viessem a explorar o Novo Mundo implicou uma empreitada que apenas poderia ser posta em prática pelas vias da motivação pecuniária, estando praticamente inexistente a identificação. De fato, a grande diferença entre as condições naturais verificadas na área tropical da América e na Europa em geral repelem aqueles que poderiam atuar como potenciais povoadores. Dessa forma, a colonização somente se faria desejável no caso de haver a possibilidade de um retorno lucrativo para os empreendimentos, remunerando os esforços odiosos de se estabelecer em uma região desconhecida e de ampla diversidade.

Outra evidência para a fragilidade da motivação para a identificação no 
processo de colonização é que aqueles que aceitaram a mudança para a região de modo espontâneo somente o fizeram com a pré-condição de que pudessem atuar como dirigentes, havendo, nesse caso, outros para trabalharem para ele. Assim, a mão de obra base foi a escravidão, a qual é chamada para atuar pela motivação da compulsão. É certo que a escassez de mão de obra em Portugal e Espanha não permitiram maior uso de trabalhadores brancos nas colônias. Entretanto, em condições distintas, como as colonizações lideradas pela Inglaterra, a qual, por sua vez, verificava abundância no número de mão de obra disponível, houve forte presença de escravos nas regiões fora das zonas temperadas. Assim como nas colônias da América do Sul, estas tiveram a forte presença da instituição da propriedade absenteísta e do uso da compulsão como motivação para o trabalho.

Ambos os fatores determinantes da instituição da propriedade absenteísta, ou seja, a elevada concentração de propriedade e a fragilidade da motivação pela identificação, são concebidos tanto como causa da mentalidade predatória portuguesa no trato com a nova região quanto como condicionadores dos hábitos de vida constituídos pelas experiências enfrentadas por aqueles que vieram para a colônia.

Em outras palavras, a inclinação predatória que dominou a mente dos agentes pioneiros no processo de formação do Brasil foi determinante para a configuração inicial das instituições que viriam a regular a atividade econômica e os demais níveis da vida social. Por sua vez, essas instituições atuariam reforçando as propensões instintivas que lhes deram sentido, orientando os hábitos de emulação social e o sistema de motivação para atuarem em linha com os imperativos da inclinação predatória. Esse processo gera um ciclo de perpetuação de hábitos e instintos que condicionarão as ações e pensamentos das gerações seguintes.

Inclusive, tem-se que as colônias tropicais conservaram o seu caráter mercantil nos anos que se sucederam à sua independência. Para Caio Prado Jr., "não sofremos nenhuma descontinuidade no decorrer da história da colônia", e o período pós independência "não é senão um elo da mesma cadeia que nos traz desde o nosso mais remoto passado" (Prado Jr., [1942] 2017, p. 12). A presença da instituição da propriedade absenteísta, como norteadora do processo de formação da nação, fez com que tudo se dispusesse para atender aos objetivos comerciais da colonização.

Se vamos à essência da nossa formação, veremos que na realidade nos constituímos para fornecer açúcar, tabaco, alguns outros gêne- 
ros; mais tarde ouro e diamantes; depois, algodão, e em seguida café, para o comércio europeu. Nada mais que isto. (Prado Jr., [1942] 2017, p. 27)

Em suma, foi este caráter mercantil que definiu o sentido da evolução colonial brasileira e que, pelos mecanismos de transmissão hereditária de hábitos institucionalizados, presentes na dinâmica social, fez prevalecer ainda no século XX uma configuração institucional com base na inclinação predatória.

Outro autor que deu importância ao "sentido" em seu esforço de interpretar o país foi Sérgio Buarque de Holanda. Em seu livro clássico Raízes do Brasil (1936), o intérprete remonta ao estilo de vida do português para explicar os hábitos mentais do povo brasileiro e suas implicações no desenvolvimento da região. Para esse autor, a dificuldade na organização social que o Brasil enfrenta, desde sua época colonial, deve-se pelo processo malsucedido de emular a cultura europeia em um território estranho às tradições milenares do velho continente.

Segundo Sérgio Buarque, a dificuldade na constituição de uma unidade nacional, essencial para a instauração da "ordem e a tranquilidade entre os cidadãos", deve-se à mentalidade "aventureira" dos povos ibéricos. Tal mentalidade se caracteriza pelo desgosto com a "religião do trabalho e o apreço à atividade utilitária" (Holanda, 1995, p. 44).

Aqui há uma certa convergência entre a qualificação feita por Sérgio Buarque e as categorias instintivas desenvolvidas por Veblen. $\mathrm{O}$ autor brasileiro utiliza um esquema analítico em que se qualificam as formas de vida coletiva por dois tipos de princípios que, conforme ele, "regulam diversamente as atividades dos homens" (Holanda, 1995, p. 56). Esses princípios estabelecem os meios de conduta dos indivíduos de uma sociedade, sendo tipificados como o "aventureiro" e o "trabalhador".

O primeiro tipo está relacionado à filosofia de um povo que visa como ideal "colher o fruto sem plantar a árvore" (Holanda, 1995, p. 56), ou seja, enaltece recompensas imediatas, sem muito esforço produtivo, e que atua em função do triunfo a ser conquistado. Para Sérgio Buarque, esse tipo humano é caracterizado como audacioso, imprevisível, instável, irresponsável e que prefere a vagabundagem ao esforço do trabalho. Já o trabalhador julga as atitudes do aventureiro como imorais e fúteis. Dá mais valor ao esforço desprendido para a superação das dificuldades do que os resultados obtidos. Dessa forma, a ética do trabalho "só atribuirá valor moral positivo às ações 
que sente ânimo de praticar" (Holanda, 1995, p. 56), sem dar muita importância para as perspectivas pecuniárias de seu empenho.

Para Sérgio Buarque, foi, portanto, o gosto pela aventura, a ânsia de prosperidade sem custo, de títulos honoríficos, de posições e riquezas fáceis, a característica principal que influenciou a formação da nação brasileira.

O que o português vinha buscar era, sem dúvida, a riqueza, mas riqueza que custa ousadia, não riqueza que custa trabalho. A mesma, em suma, que se tinha acostumado a alcançar na Índia com as especiarias e os metais preciosos. Os lucros que proporcionou de início, o esforço de plantar a naca e fabricar o açúcar para mercados europeus, compensavam abundantemente esse esforço - efetuado, de resto, com as mãos e os pés dos negros -, mas era preciso que fosse muito simplificado, restringindo-se ao estrito necessário às diferentes operações. (Holanda, 1995, p. 63)

Essa tipificação feita pelo autor, qualificando tipos de conduta, apresenta forte conciliação com as categorias instintivas empregadas por Veblen em sua teoria. As condutas promovidas pelo instinto para o trabalho eficaz e predatório são diretamente correspondentes ao homem trabalhador e aventureiro na obra de Sérgio Buarque. Entretanto, deve-se atentar para algumas diferenças em sua aplicação para explicar as sociedades e suas trajetórias de desenvolvimento.

Sérgio Buarque associa o tipo humano dominante no Brasil como sendo aquele que apresenta um modo de comportamento mais emotivo, caracterizado como "homem cordial", em detrimento do uso de uma maior carga de racionalidade nas tomadas de decisão e na composição dos órgãos administrativos. Para o autor, essa emotividade é um traço definido do caráter brasileiro e que advém dos padrões de convívio "informados no meio rural e patriarcal" (Holanda, 1995, p. 257). Com isso, tem-se como resultado a negação da impessoalidade em todas as esferas da interação social e econômica. Nas palavras do intérprete, "é possível acompanhar, ao longo de nossa história, o predomínio constante das vontades particulares que encontram seu ambiente próprio em círculos fechados e pouco acessíveis a uma ordenação impessoal" (Holanda, 1995, p. 257). Por sua vez, a ausência do caráter da impessoalidade implica a escolha dos homens que irão atuar nas funções públicas, de modo que esta ocorrerá de acordo com a confiança pessoal dos detentores do poder e "muito menos de acordo com as capacidades próprias" (Holanda, 1995, p. 257). 
Diante disso, Sérgio Buarque assume a hipótese de que o Brasil é uma "sociedade pré-moderna e dominada pela emotividade e pessoalidade" (Souza, 2015, p. 32). A diferença em relação a Veblen é que a categoria dos instintos - que em Sérgio Buarque aparece como tipos trabalhador e aventureiro carrega consigo conjuntos de sentimentos, de modo que a racionalidade não é passível de atuar sem a "contaminação" das emoções, pois são estas que fornecem a finalidade para o que deve ser deliberado (Veblen, 1914). Portanto, em linha com a abordagem deste artigo, não é razoável qualificar a cordialidade como responsável principal pela ineficiência e pelo atraso da sociedade brasileira, pois é um hábito de conduta passível de compatibilidade tanto com as inclinações "aventureiras" quanto com as "trabalhadoras".

A cordialidade como forma de emulação social, cujo intuito é a conquista de estima pelo grupo, pode ter como base o instinto predatório quando associada a ações de ostentação de riqueza e poder. Em Theory of the leisure class, em que Veblen analisa os hábitos sociais da elite norte-americana, são citadas situações em que um meio de provar proezas, além da ostentação de posses, é estender os hábitos de ócio para aqueles indivíduos que vivem próximos aos donos do poder. É o caso das esposas, filhos, alguns escravos e demais amigos da família. Já em The instinct of workmanship and the irksomeness of labor, a cordialidade é mencionada como hábito associado ao instinto para o trabalho eficaz, pois é referente ao senso de solidariedade, serventia e coletivismo. Nesse caso, a honorabilidade e a demonstração de capacidade estão atreladas diretamente à eficiência, produtividade e utilidade.

Outro equívoco de Sérgio Buarque, à luz da abordagem vebleniana, é a sua análise reducionista das instituições brasileiras. Para o intérprete brasileiro, a cultura e as instituições que tomam a sociedade dos trópicos são resultado direto da importação do meio de vida português, mal-adaptado em um novo ambiente. De acordo com ele, essa transposição foi tão rígida que "nem o contato e a mistura de raças indígenas ou adventícias fizeram-nos tão diferentes dos nossos avós de além-mar como às vezes gostaríamos de sê-lo", afirmando ainda que "de lá nos veio a forma atual de nossa cultura; o resto foi matéria que se sujeitou mal ou bem a essa forma" (Holanda, 1995, p. 47).

Esse processo de transposição institucional é estranho para a corrente institucionalista pois argumenta-se que as instituições são derivadas de um processo que envolve afloração de instintos, habituação e deliberação sobre seus resultados. Dessa forma, mesmo diante da transferência direta de instituições e hábitos de Portugal para a colônia nas Américas, não se pode afirmar 
que estas permaneceram imutáveis e nem que atuaram perseguindo os mesmos objetivos. Além disso, o processo prevê o surgimento de novos hábitos e instituições, uma vez que as condições de interação são distintas do ambiente de origem. ${ }^{7}$

As instituições sociais e econômicas que dirigiram a vida colonial brasileira, como a propriedade absenteísta e o clã patriarcal, não podem ser interpretadas como redutíveis às que predominaram na Metrópole. As instituições que aqui se desenvolveram, como o sistema de motivação pautado na compulsão do trabalho escravo e no desejo desenfreado de ganho pecuniário por parte dos colonos, são frutos das inclinações instintivas afloradas pelas experiências iniciais na região, cuja falta de identificação com as condições ambientais e com os nativos aqui preestabelecidos inibia a formação de hábitos mentais com base no instinto para o trabalho eficaz.

Para Caio Prado Jr., o clã patriarcal da forma como é vista no Brasil "é algo de específico da nossa organização" (Prado Jr., [1942] 2017, p. 387). Mesmo que essa instituição tenha sido verificada na Metrópole, o que determinou o seu desenvolvimento na região, como também a sua abrangência na determinação da dinâmica social, foram o ambiente e o regime econômico instaurado desde os primeiros momentos do processo de colonização.

Um exemplo importante é o resultado da colonização inglesa na América do Norte. Para Sérgio Buarque, a Inglaterra era um país onde o tipo dominante era o indivíduo de característica trabalhadora, mas sua colonização nos Estados Unidos criou polos onde imperava tanto o tipo "trabalhador" quanto o tipo "aventureiro", este em especial nas colônias do sul. Nesse caso, tem-se que, na região do norte, a distribuição das terras foi realizada de forma menos concentrada, com o predomínio da pequena posse de tipo camponês. Consequentemente, o poder da propriedade foi limitado nos estágios iniciais da colonização e, com isso, foi possível maior espaço para a motivação da identificação na estrutura produtiva. Já nas colônias do sul da América do Norte, onde vigora um clima subtropical, especificamente mais úmido e quente, estabeleceu-se um modelo semelhante ao que se verificou na América do Sul, com forte presença dos proprietários de grandes lotes de terras

\footnotetext{
${ }^{7}$ Aqui se pode incluir as contribuições de Raymundo Faoro, que, em sua obra Os donos do poder (1958), avança em relação a interpretação de Sérgio Buarque, ao mostrar como o estamento burocrático, ou seja, as instituições formais do Estado brasileiro, surge a partir dos interesses predatórios da elite local e, consequentemente, atua reforçando os instrumentos de poder utilizados para restringir os anseios do restante da sociedade. Nesse caso, o autor entendia que esse estamento burocrático surgiu no seio do padrão de domínio que se instaurou no período colonial, e não derivado apenas de uma transposição institucional da burocracia portuguesa.
} 
e o predomínio do trabalho escravo, o que acentuou a propriedade como instrumento de poder e, consequentemente, a remuneração e compulsão como formas dominantes de motivação para o trabalho e nas relações econômicas em geral.

Sabe-se que a teoria dos hábitos e instintos de Veblen faz um contraponto às abordagens que reduzem a explicação das sociedades humanas a partir da cultura, como é o caso de Sérgio Buarque. Seguindo a análise das ideias do autor institucionalista, pode-se afirmar que a motivação e a emulação pecuniárias são resultados não apenas da cultura, mas também do nível de abundância e distribuição dos recursos materiais.

ParaVeblen (1898), a presença de excedentes produtivos em uma sociedade cria condições para a afloração de propensões predatórias, uma vez que o esforço para a produtividade perde seu status de honorabilidade. Já em Galbraith ([1967] 1982), tem-se que sociedades nas quais há elevada concentração de propriedade, e portanto seu uso como instrumento de poder, tende a haver o predomínio de sistemas de motivação voltados para a remuneração e a compulsão. Sendo assim, conforme a abordagem deste artigo, o tipo de colonização que se teve no Brasil não foi dependente do fator cultural, mas sim dos instrumentos de poder e do sistema de motivação que resultaram do contexto material e distributivo.

Uma interpretação que, em certa medida, é semelhante pode ser vista nos trabalhos de Acemoglu, Johnson e Robinson (2001, 2002), os quais fizeram uso da econometria para testar a tese das influências do tipo de colonização e das condições materiais iniciais no desenvolvimento dos países. Apesar de concordar sobre a associação entre trajetórias de desenvolvimento e tipo de colonização, a relação de causalidade sobre os fatores que implicaram o tipo de colonização é diferente entre a teoria desses autores e a abordagem vebleniana aqui apresentada.

Para Acemoglu, Johnson e Robinson (2001, 2002), os determinantes iniciais do tipo de colonização seriam mais as condições da colônia do que os interesses ou as capacidades da metrópole. Ou seja, onde se verificou um ambiente mais receptivo aos europeus haveria uma tendência a atrair colônias de povoamento, enquanto as regiões em que o ambiente foi mais hostil, medido pela mortalidade potencial do colono, tenderiam a incentivar tipos de instituições extrativas. Resumindo, a dotação de fatores determina o tipo de colonização, que, consequentemente, afeta as instituições sociais que orientaram os rumos posteriores. 
Já em relação à abordagem vebleniana deste artigo, a causalidade é diferente, pois se chama atenção para as motivações iniciais quanto ao uso dos recursos da colônia e a distribuição, que foram fundamentais na determinação do tipo de colonização. Isso, por sua vez, influenciou na estrutura institucional e na consequente trajetória de desenvolvimento socioeconômico da região.

Em suma, não é exclusivamente a cultura ou a dotação inicial dos fatores que importam para definir o sentido das instituições e do desenvolvimento de uma sociedade. Mais do que isso, é preciso levar em conta como os instrumentos de poder e o sistema de motivação emergem como resultado da interação entre tais elementos. É a partir desse contexto que os instintos são aflorados na mente dos agentes e, consequentemente, concebem as diretrizes das instituições.

Ao contrário da causalidade apresentada por Acemoglu, Johnson e Robinson $(2001,2002)$, considera-se que as instituições extrativas da colonização do Brasil surgiram sem que aqui se tivesse experimentado um estágio de escassez. Isso, mais a estrutura proprietária fortemente concentrada, criou condições favoráveis para a dominância do instinto predatório na mente da elite colonial.

Já a despeito da interpretação de Sérgio Buarque, tem-se que o tipo de colonização brasileira deve ser atribuído mais às experiências e motivações iniciais na nova região do que tomado propriamente como fruto direto das instituições culturais portuguesas. Nesse caso, infere-se que ações e instituições de cunho predatório podem surgir em qualquer tipo de cultura.

Diante das discussões feitas, afirma-se que o caso brasileiro se caracteriza como uma sociedade que surgiu como subproduto da empresa de exploração, no qual o sistema econômico antecede a formação da sociedade. Em um primeiro momento, as instituições de cunho predatório não são limitadas pelos imperativos da inclinação do trabalho eficaz, tornando mais difícil o surgimento da identificação como motivação para a ação econômica no desenrolar do processo de desenvolvimento.

Nos estágios iniciais da colonização, a compulsão era utilizada como mecanismo principal para a motivação dos escravos no dia a dia do trabalho. O medo do açoite e das privações dos meios básicos de subsistência, como a alimentação, era frequentemente evocado para limitar qualquer desejo de ação com intuito de serventia e utilidade. Já pelo lado dos proprietários de terras, a falta de identificação com o novo ambiente não lhe aflorava qualquer 
vontade que não fosse o de obter o maior lucro possível através da exploração das riquezas naturais e do trabalho alheio.

Assim, as instituições resultantes dos hábitos germinados pelas inclinações predatórias dos colonos atuaram reforçando aqueles instintos que lhes deram base inicial e que, consequentemente, replicaram essas motivações no decorrer da trajetória de desenvolvimento do país. Esse processo, iniciado em meados do século XVI, em uma economia dominantemente agrária, voltada para atender ao consumo externo, criou uma sociedade com configuração institucional semelhante à primeira tipologia apresentada. Ou seja, uma sociedade caracterizada pelo uso da propriedade como principal instrumento de poder, que, por sua vez, cria condições para o estabelecimento da remuneração (latifundiários) e compulsão (escravos) como sistema de motivação dominante. Como resultado, tem-se no Brasil um país com hábitos de emulação baseados no ócio e no consumo conspícuos, além de uma cordialidade voltada para a ostentação de poder e riqueza, que são facilmente verificados no comportamento da elite nacional e emulados pela classe média.Tais hábitos, por conseguinte, fecham o ciclo ao selecionar a propriedade como o melhor instrumento de poder possível para a realização da emulação pecuniária.

\section{Considerações finais}

Este artigo teve como objetivo principal o resgate da teoria dos instintos de Veblen e, consequentemente, sua incorporação para a concepção de um modelo institucionalista que visa explicar as instituições e as regularidades do sistema econômico das sociedades, além do seu uso para interpretar o sentido da colonização brasileira. O modelo em questão fornece uma tipologia que contribuirá para explicar o sentido dos sistemas econômicos e de suas instituições. Essa abordagem leva em conta os instintos aflorados em um sistema composto por: hábitos de emulação social, instrumentos de poder e um sistema de motivação presente no interior das organizações produtivas.

Em suma, as fontes de poder têm a capacidade de interferir no sistema de motivação que determinará os meios utilizados para coagir os indivíduos a se associarem às organizações. Por sua vez, as motivações são mecanismos determinantes da afloração instintiva que direcionam o processo de habituação. As instituições, derivadas dos objetivos fornecidos pelos instintos, irão configurar as formas sociais de emulação e, com isso, atuar como mecanismo de seleção, ou validação, dos instrumentos de poder. 
Sobre a trajetória de desenvolvimento do Brasil, buscou-se demonstrar que o período colonial se desdobrou em uma dinâmica na qual a sociedade inicialmente formada foi dominada pela propriedade como instrumento de poder, sendo a remuneração e a compulsão motivações principais para a ação econômica e social dos latifundiários e escravos. Essa configuração é tanto resultado quanto causadora da dominância do instinto predatório. Consequentemente, tem-se uma sociedade com hábitos de emulação baseados no ócio e no consumo conspícuos, além de uma cordialidade voltada para a ostentação de poder e riqueza. Esses hábitos formam uma estrutura social que reproduz experiências que, por sua vez, reforçam a inclinação predatória aflorada desde o início da formação desta nação.

No geral, a trajetória de formação do país criou poucas oportunidades para a afloração do instinto para o trabalho eficaz. Esse processo impactou tanto a elite quanto as demais classes. De um lado, o modo de exploração escravista dificultou a identificação como motivação para a vida social e econômica por parte dos primeiros trabalhadores da região. Já do lado dos latifundiários, a motivação que liderou suas ações foi o desejo de acumulação de riqueza, partindo da exploração do trabalho escravo e da extração de recursos da terra. Logo, instituir a identificação como motivação principal da ação econômica se tornou uma alternativa improvável desde o início e, por esse motivo, pode ter tido implicações importantes no desenrolar do processo de desenvolvimento que o país experimentou desde então, até os dias atuais.

\section{Referências}

ACEMOGLU, D.; JOHNSON, S.; ROBINSON, J. The colonial origins of comparative development: an empirical investigation. The American Economic Review, v. 91, n. 5, p. 1369-1401, 2001.

ACEMOGLU, D.; JOHNSON, S.; ROBINSON, J. Reversal of fortune: geography and institutions in the making of the modern world income distribution. The Quarterly Journal of Economics, v. 117, n. 4, p. 1231-1294, jan. 2002.

BALDWIN, R. E. Patterns of development in newly settled regions. The Manchester School, v. 24, n. 2, p. 161-179, 1956.

CAVALIERI, M.A.R. O surgimento do institucionalismo norte-americano: ensaio 
sobre o pensamento e o tempo de ThorsteinVeblen. Belo Horizonte: UFMG, 2009. Tese (Doutorado em Ciências Econômicas da UFMG).

ENGERMAN, S.; SOKOLOFF, K. Factor endowments, institutions, and differential paths of growth among new world economies: a view from economic historians of the United States. In: HABER, S. How Latin America fell behind. Stanford CA: Stanford University Press, 1997.

FAORO, R. Os donos do poder: formação do patronato político brasileiro. Porto Alegre, Rio de Janeiro, São Paulo: Ed. Globo, 1958.

FREITAS, T. R. O resgate da Teoria dos Instintos de Veblen e suas implicações para o debate institucionalista do desenvolvimento. Porto Alegre: UFRGS, 2019. Tese (Doutorado em Ciências Econômicas da UFRGS).

GALBRAITH, J. K. The affluent society. Boston: Houghton Mifflin Harcourt, 1998.

GALBRAITH,J.K. American capitalism: the concept of countervailing power. Classics in Economics Series. New Brunswick, NJ and London:Transaction, 1993.

GALBRAITH, J. K. A anatomia do poder. São Paulo: Pioneira, 1984.

GALBRAITH, J. K. (1967). O novo estado industrial. São Paulo: Abril Cultural, 1982.

HODGSON, G. M.The approach of institutional economics. Journal of economic literature, v. 36, n. 1, p. 166-192, 1998.

HODGSON, G. M. Economics and evolution: bringing life back into economics. University of Michigan Press, 1996.

HODGSON, G. M. The evolution of institutional economics. Routledge, 2004.

HODGSON, G. M. Some myths of veblenian institutionalism. Thorstein Veblen and the revival of free market capitalism. Cheltenham, UK, Northampton, MA, USA: Edward Elgar, p. 127-47, 2007. 
HODGSON, G. M. What is the essence of institutional economics? Journal of economic issues, v. 34, n. 2, p. 317-329, 2000.

HOLANDA, S. B. Raízes do Brasil. São Paulo: Companhia das Letras, 1995.

JAMES, W. The principles of psychology, volume 2. London: Macmillan, 1890.

LINDBLOM, C.E. Politics and markets: the world's political economic systems, New York: Basic Books, 1977.

MCDOUGALL,W. An introduction to social psychology. London:Methuen, 1908.

MONASTERIO, L.; EHRL, P. Colônias de povoamento versus colônias de exploração: de Heeren a Acemoglu. Brasília, Rio de Janeiro: Ipea, 2015.

NORTH, D. C. Agriculture in regional economic growth. Journal of Farm Economics, v. 41, n. 5, p. 943-951, 1959.

PRADO JR., C. P. (1942). Formação do Brasil contemporâneo 1942 2017. São Paulo: Companhia das Letras, 2017.

SCHWARCZ, L. M.; STARLING, H. M. Brasil: uma biografia. São Paulo: Companhia das Letras, 2015.

SOUZA, J. A tolice da inteligência brasileira: ou como o país se deixa manipular pela elite. Rio de Janeiro: Leya, 2015.

STANFIELD, J. R.; WRENN, M. John Kenneth Galbraith and original institutional economics. Journal of Post Keynesian Economics, v. 28, n. 1, p. 26-45, 2005.

VEBLEN,T. The engineers and the price system. New York: BW Huebsch, 1921.

VEBLEN, T. The instinct of workmanship and the irksomeness of labor. American Journal of Sociology, v. 4, n. 2, p. 187-201, 1898.

VEBLEN, T. The instinct of workmanship and the state of the industrial arts. BW Huebsch Inc., 1914. 
VEBLEN, T. (1904). The theory of business enterprise. New Brunswick, N.J.: Transaction Publishers, 1978.

VEBLEN,T. (1899). Theory of the leisure class. Oxford World's Classics. Transaction Publishers, 2007. 